\title{
The Effect of ABO Blood Types on Periodontal Status
}

\author{
Turgut Demira, DDS, PhD \\ Adnan Tezela, DDS, PhD \\ Recep Orbaka, DDS, PhD \\ Abubekir Eltas ${ }^{\mathrm{a}}$, DDS \\ Cankat Kara ${ }^{a}$ DDS, PhD \\ Fahri Kavruta, DDS, PhD
}

\section{ABSTRACT}

Objectives: The purpose of the present study was to determine whether there was a relationship between periodontal diseases and ABO blood groups.

Methods: This epidemiological study was carried out on 1351 subjects who were randomly selected from individuals referred to the Faculty of Dentistry clinics for periodontal treatment or for other reasons regarding dental health. The study based on periodontal condition, blood group, and medical history. The subjects were divided into three groups as those with gingivitis, periodontitis, and the healthy ones. The effects of blood subgroups on periodontal health, gingivitis and periodontitis were investigated separately.

Results: A relatively higher percentage of $A$ group patients was found in gingivitis group and relatively higher percentage of 0 group patients was found in periodontitis group. A significant relationship was also determined between Rh factor and gingivitis.

Conclusions: ABO blood subgroups and Rh factor may constitute a risk factor on the development of periodontal disease. However, long-term studies are needed to make a more comprehensive assessment of the effects of ABO group on periodontal diseases. (Eur J Dent 2007;1:139-143)

Key words: ABO; Blood; Periodontal disease; Rh factor; Gingivitis.

\section{INTRODUCTION}

The first human blood group, that is, the ABO system discovered by Landsteiner, ${ }^{1}$ is the most commonly used blood system although many blood systems have been identified so far. The discovery of $A B O$ system and findings of red cell agglutination in serum and recognition of blood groups laid the scientific basis for safe practice of blood transfusion. ${ }^{2}$ The other important blood systems are the Rhesus (Rh) and the MN system. ABO

a Department of Periodontology, Atatürk University, Faculty of Dentistry, Erzurum, TURKEY

- Corresponding Author: Yrd. Doç. Dr. Turgut Demir Atatürk Üniversitesi Diș Hekimliḡi Fakültesi Periodontoloji Anabilim Dalı 25240, Erzurum, TÜRKiYE. E-mail: turgdemirahotmail.com and $\mathrm{Rh}$ systems have major clinical significance and they are determined by the nature of different proteins present on the surface of red blood cells. The antigens of the ABO system are an integral part of the red cell membrane and they are also found in plasma and other body fluids.

All human populations share the same blood systems, although they differ in the frequencies of specific types. The distribution patterns of $\mathrm{ABO}$ and $\mathrm{Rh}$ systems are complex around the world. Some variation may even occur in different areas within one small country. ${ }^{3}$ The blood group distribution also shows variety according to races. ${ }^{4}$ It was reported that the group $A$ has a wider distribution in Eskimos, the group B in Chinese and Indians, the group 0 , on the other hand, in American and 
Canadian Indians and Czechoslovakians and those living in Kenya. ${ }^{4}$ According to statistical distribution of the ABO blood types in the Turkey, $42.5 \%$ had type $A$ and $33.7 \%$ had type 0 and $15.8 \%$ had type $B$, and $8.0 \%$ had type $A B$ blood. ${ }^{5}$

When the rate of $\mathrm{Rh}+$ is considered, it was reported to be about $85 \%$ in all the population. However, varying percentages were reported in various countries of the world (Kenya 96\%, India 99\%, Iran 90\%, Turkey $87 \%$ ). ${ }^{4}$

ABO blood groups are the most investigated erythrocyte antigen system, and owing to ease of identifying their phenotypes, they have been used as genetic markers in studies of their associations with various diseases. ${ }^{6,7}$ Studies from the 1950s demonstrated that blood group 0 is associated with duodenal ulcer disease, while gastric ulcer and gastric carcinoma are associated with blood group $A .^{8}$

During the last few decades, several reports have suggested that $A B O$ blood groups, in particular non-0 blood groups, are associated with the risk of ischemic heart disease and of developing severe manifestations of atherosclerosis. ${ }^{9-12} \mathrm{Re}$ sults from the Farmingham study ${ }^{13}$ and several other reports indicated that the incidence of ischemic heart disease might be higher in subjects of blood group A or its subgroups. Stakisaitis ${ }^{10}$ found that the blood group B might be related to coronary atherosclerosis in Lithuanian women. In apparent contradiction, Michell ${ }^{14}$ showed that towns with a higher prevalence of blood group 0 had higher rates of cardiovascular mortality.

Although several studies have been carried out to investigate relationships between the $A B O$ blood groups and the incidence of certain diseases in medicine, little investigation has been made to explore the relationships between $A B O$ blood groups and the incidence of oral and dental diseases. Aitchison and Carmichael ${ }^{15}$ studied the distribution of blood groups within two groups, one of whom were the random patients attending the dental hospital and the other consisting of cases with rampant caries. Barros and Witkop ${ }^{16}$, on a large group of Chileans, found no association between the D.M.F scores for caries and ABO Blood groups.

It is well known that periodontal diseases have high incidence in population. ${ }^{17}$ Although bacterial plaque is considered the primary extrinsic etiolog- ic agent in periodontal diseases, ${ }^{17,18}$ our purpose in this study was to describe whether there is a relationship between $\mathrm{ABO}$ blood groups and periodontal diseases in a group of Turkish people who have same social and economic conditions.

\section{MATERIALS AND METHODS}

The present investigation was carried out on 1351 subjects, 647 male and 704 female, aged 17 to 63. Subjects were selected from among patients who were referred to the clinics of Faculty of Dentistry at Atatürk University for periodontal treatment and for other dental health reasons. Certain criteria were followed in order to bring forward ABO blood groups of individuals included in the research. It was demanded according to the selection criteria that:

1. All subjects had at least 20 teeth and had received no periodontal treatment or antibioticrelated therapy for medical or dental reasons 3 month prior to the study.

2. They had no history of systemic disease such as diabetes, leukemia, metabolic bone disease or epilepsy.

3. They were non smokers.

4. They had similar socio-economic status.

5. The gingivitis subjects displayed less than 3 $\mathrm{mm}$ of attachment loss, periodontal pockets depth less than $3 \mathrm{~mm}$, no radiographic bone loss but displayed gingivitis sign (Gingival bleeding, color, gingival contour, position and surface texture in the gingival. Periodontitis subjects exhibited at least one site evidence of radiographic bone loss, attachment loss more than $3 \mathrm{~mm}$, periodontal pockets depth more than $4 \mathrm{~mm}$. Healthy subjects displayed less than $3 \mathrm{~mm}$ of attachment loss, periodontal pockets depth less than $3 \mathrm{~mm}$, no radiographic bone loss and no gingivitis sign.

The clinical oral examination was carried out after the subject had been interviewed on behavior and socioeconomic background. Having been informed about the method and purpose of the study, the patients were asked for their consent to participation.

All the clinical measurements were made using a manual periodontal probe (Williams' periodontal probel on the gingival area adjacent to the teeth in each patient. The subjects were examined clinically for the presence of plaque, gingival bleeding, clinical attachment level, probing 
pocket depth. According to index scores, subjects were divided into three groups: Group I consisted of 356 patients with healthy gingiva (188 females, 168 Males); group II consisted of 441 patients with gingivitis (255 Females, 186 Males); and group III consisted of 554 patients with periodontitis (261 Females, 293 Males). Group I consisted of the subjects selected randomly from patients who applied to our faculty with reasons other than periodontal diseases such as orthodontic reasons and dental caries. Then, the subjects in all three groups were referred to the Hematology Department at the Faculty of Medicine at Atatürk University for determination of $A B O$ blood subgroup. Data were analyzed with Chi-Square test. A P value of .05 was considered significant for all statistical test conducted.

\section{RESULTS}

In the 1351 blood samples surveyed, A blood group (48.5\%) and 0 blood group (30.3\%) were more common, $89.9 \%$ had Factor Rh positive, and $10.1 \%$ had Factor Rh negative. The data of a study ${ }^{4}$ performed in Erzurum, representing the distribution of the blood subgroups among the general population and involving 10493 subjects, was used to control the homogeneity of the study group by taking into consideration the regional changes of ABO blood subgroup. When compared with the data obtained in the mentioned study, the blood group distribution in the present study was determined to indicate no significant change.

The results were compared with those of random samples obtained from Ataturk University medical faculty blood donors. ${ }^{4}$ The blood group distribution within all the three groups in the present study was determined to indicate no significant change $(P>05)$. The observation established the homogeneity and unbiased nature of the study group as well as pointing to the natural distribution that is likely to exist in a population.

Table 1 shows frequency distribution of the ABO blood groups in 1351 subjects and the comparative expected frequency distribution of the same blood groups obtained from 10493 controls. Table 2 shows frequency distribution of the ABO blood groups in 1351 patients with various grades of periodontal involvement. From the data, one finds a higher frequency at periodontal diseases in subjects with group $A$ and 0 . There is a relatively high percentage of blood group $A$ patients $(61.5 \%)$ in gingivitis and relatively high percentage of blood group 0 patients (41.5\%) with periodontitis $(P<.05)$.

The Rh factor distribution status was compared among the 1351 subjects in the study group and the 10493 subjects in the control group, no significant difference was found regarding the distribution of $\mathrm{Rh}$ factor $(\mathrm{P}>$.05). It was also determined that there was a relationship between Rh (+) factor and gingivitis in border line $(\mathrm{P}<.05)$.

\section{DISCUSSION}

Periodontal diseases, including gingivitis and periodontitis, are serious infections that, if left untreated, may lead to tooth loss..$^{17}$ The principal cause of periodontal diseases is bacterial plaque. However, a wide range of background factors such

Table 1. Frequency of the ABO blood groups in general population and in study group.

\begin{tabular}{l|c|c|c|c|c|c|c} 
& & $\mathrm{A}$ & $\mathrm{B}$ & $\mathrm{AB}$ & $\mathrm{0}$ & $\mathrm{Rh}+$ & $\mathrm{Rh}-$ \\
\cline { 2 - 10 } & $\mathrm{N}$ & $\%$ & $\%$ & $\%$ & $\%$ & $\%$ & $\%$ \\
\cline { 2 - 9 } & 10493 & 46 & 14.5 & 7.2 & 32.3 & 87 & 13 \\
General Population & 1351 & 48.5 & 14.3 & 6.9 & 30.3 & 89.9 & 10.1
\end{tabular}

Table 2. Frequency of the ABO Blood groups in study group.

\begin{tabular}{lcc|c|c|c|cc} 
& & $\mathrm{A}$ & $\mathrm{B}$ & $\mathrm{AB}$ & $\mathrm{O}$ & $\mathrm{Rh}+$ & $\mathrm{Rh}-$ \\
\cline { 2 - 9 } & $\mathrm{n}$ & $\%$ & $\%$ & $\%$ & $\%$ & $\%$ & $\%$ \\
\hline Study Group (Total) & 1351 & 48.5 & 14.3 & 6.9 & 30.3 & 89.9 & 10.1 \\
Group I (Healthy) & 356 & 48.1 & 14.1 & 7 & 30.8 & 91 & 9 \\
Group II (Gingivitis) & 441 & 61.5 & 7.7 & 4.7 & 26.1 & 83.4 & 16.6 \\
Group III (Periodontitis) & 554 & 38 & 14.7 & 5.9 & 41.4 & 90.4 & 9.6 \\
\hline
\end{tabular}


as age, sex, education, place of residence, oral hygiene habits, socio-economic status, genetic characteristics and smoking habits have been identified as risk factors for the occurrence of periodontal diseases. ${ }^{17-19}$

It is known that ABO blood types indicate differences in terms of their proportion according to races. ${ }^{4}$ It is also known that periodontal diseases show proportional differences in distribution among races. When this point is taken into consideration, the question arises whether or not the proportion of $\mathrm{ABO}$ blood subgroup distribution is effective on the proportion of distribution of periodontal disease in various societies. Surprisingly, little investigation has been made to explore the ABO blood groups and the incidence of oral and dental diseases. In the earliest investigation on this matter, Suk ${ }^{20}$ suggested that particular blood groups and a tendency towards caries might be constitutional characters and they were not particularly related to race, though the 0 group and good teeth were less common in civilized people than in primitive races. Suk's investigation was followed by a study carried out by Aitchison and Carmichael, ${ }^{15}$ which revealed a relationship between the patient's susceptibility to caries and his blood group.

In a study carried out by Arowojolu et al, ${ }^{21}$ it was stated that there was a relationship between juvenile and non-juvenile periodontitis and hemoglobin type $A$. The influence of $A B O$ blood types on the risk of developing oral diseases has been the subject of discussion. Some authors ${ }^{22,23}$ claimed that, ABO blood types constituted an increased risk for the development of oral diseases whereas a small group of researchers failed to find this increased risk. ${ }^{24}$ Above mentioned studies provided preliminary data concerning the associations between ABO blood groups and periodontal diseases. The present study researched the relationship between $\mathrm{ABO}$ blood subgroups and periodontal diseases in the light of the above data.

In this study, it was determined that there was a relatively higher percentage of $A$ blood group in patients with gingivitis and a relatively higher percentage of $\mathrm{O}$ blood group in patients with periodontitis. Similarly, Gawrzewska ${ }^{22}$ found individuals of blood group 0 to have greater severity of periodontal diseases, but individuals of blood group A to have greater resistance to periodontal diseases. Suk ${ }^{20}$ found that ABO blood types had an increased effect on the risk for the development of oral diseases. Pradhan et $\mathrm{al}^{23}$ also found significant differences when $A B O$ blood groups were related to four grades of periodontal involvement. In one early investigation, O'Rark and Lyschon ${ }^{25}$ found a statistical significance regarding the relation between M.N. blood groups and caries history. On the contrary, Barros and Witkop ${ }^{16}$ stated that there were no significant differences between subjects with or without periodontal diseases regarding $\mathrm{ABO}$ blood group.

Upon comparison of the $\mathrm{Rh}$ factor distribution status between the 1351 subjects in the study group and the 10493 subjects in the control group, no significant difference was found regarding the distribution of $R$ factor $(P>.05)$. A significant relationship between $\mathrm{Rh}(+)$ factor and gingivitis was determined $(P<.05)$.

\section{CONCLUSIONS}

Consequently, significant relations were determined between ABO blood types and periodontal condition, and Rh Factor and gingivitis. Considering the results of our study, it can be concluded that $\mathrm{ABO}$ blood subgroups and Rh factor could constitute a risk factor on the development of periodontal disease. However, long-term studies are needed to make a more comprehensive assessment of the effects of $A B O$ group on periodontal diseases.

\section{REFERENCES}

1. Watkins WM. The ABO blood group system: historical background. Transfus Med 2001;11:243-265.

2. Yamamoto F. Molecular genetics of $A B O$ blood groups. Vox Sang 2000;78:91-103.

3. Kolmakova GN, Kononova LL. The prevalence of ABO blood groups among persons of native nationality in Buryatia. Sud Med Ekspert 1999;42:15-16.

4. Kaya H, Gündoḡdu M, Akarsu E, Kiki I, Tekin B. The distrubition of blood groups in Erzurum. Medical Journal of Atatürk University 1999;31:20-22.

5. Turkish Redcrescent Society. www.kizilay.org.tr. 2006

6. Mourant AE, Kopec AC, Domaniewska-Sobczak K. The distribution of the human blood groups and other polymorphisms. London, Oxford University Press.1976.

7. Mourant AE, Kopec AC, Domaniewska-Sobczak K. Blood groups and diseases: a study of associations of diseases with blood groups and other polymorphisms. London, Ox- 
ford University Pres.1978.

8. Smith A, Athison S, Power E, Abdulla Y. Blood group antigens and Helicobacter pylori infections. Lancet 1994;343: 543.

9. Whincup PH, Cook DG, Phillips AN, Shaper AG. ABO blood group and ischemic heart disease in British men. $B M J$ 1990;300:1679-1682.

10. Stakishaitis DV, Ivashkiavichene LI, Narvilene AM. Atherosclerosis of the coronary arteries and blood group in the population of Lithuania. Vrach Delo 1991;8:55-57.

11. Akhund IA, Alvi IA, Ansari AK, Mughal MA, Akhund AA. Study of relationship of $\mathrm{ABO}$ blood groups with myocardial infarction and angina pectoris. J Ayub Med Coll Abbottabad 2001;13:25-26.

12. Nydegger UE, Wuillemin WA, Julmy F, Meyer BJ, Carrel TP. Association of ABO histo-blood group $B$ allele with myocardial infarction. Eur J Immunogenet 2003;30:201.

13. Garrison RJ, Havlik RJ, Harris RB, Feinleib M, Kannel WB. ABO blood groups and cardiovascular disease-the Farmingham study. Atherosclerosis 1976;25:311-318.

14. Michell JRA. An association between ABO blood group distribution and geographical differences in death-rates. Lancet 1977;5:295-297.

15. Aitchison J, Carmichael AF. The relationship between the ABO blood mutations and dental caries. Dent Pract 1962;13:93-95.

16. Barros L, Witkop CJ. Oral and genetic study of Chileans 1960 III. Periodontal disease and nutritional factors. Arch Oral Biol 1963;8:195.

17. Lindhe J, Karring T, Lang NP. Clinical periodontology and implant dentistry. Blackwell Munksgaard, $4^{\text {th }}$ ed., 2003

18. Newman MG, Takei HH, Carranza FA. Clinical Periodontology. 9 Ed. W.B.Saunders Co.Philadelphia, London, New York, St Loise, Sydney, Toronto. 2002.

19. Kinane DF. Causation and pathogenesis of periodontal disease. Periodontol 2000;2001;25:8-20.

20. Suk V. Über die beziehung zwischen gesunden Zähnen und den Zerfall und die Pflege der Zähne bei den weissen. Spisy lék Fak Masaryk Univ 1930;125 (Cited by Pradhan et al, 1971).

21. Arowojolu MO, Dosmu EB, Adingbola TS. The relationship between juvenile and non-juvenile periodontitis, ABO blood groups and haemoglobin types. Afr J Med Med Sci 2002;31:249-252.

22. Gawrzewska B. ABO, Rh and MN Blood and ABH group factors in saliva related to periodontal diseases. Czas Stomatol 1975;28:1007.

23. Pradhan AC, Chawla TN, Samuel KC, Pradhan S. The relationship between periodontal disease and blood groups and secretor status. J Periodontal Res 1971;6:294-300.
24. Kaslick RS, West TL, Chasens Al. Association between ABO blood groups, HLA antigens and periodontal diseases in young adults: a follow-up study. $J$ Periodontol 1980;51:339.

25. O'Rark WL, Leyschon C. Dental caries prevalence as related to blood groups. J Dent Res 1963;42:1530. (Cited by Pradhan et al, 1971) 